\title{
PLANEJAMENTO E PLANO DE TRATAMENTO EM ODONTOPEDIATRIA: RELATO DE CASO CLÍNICO.
}

\section{PLANNING AND TREATMENT PLAN IN PEDIATRIC DENTISTRY}

\author{
Nivia Fiuza* \\ Gerson Lopes* \\ Ana Claudia Ribas Cabral** \\ Flávia Ribeiro de Carvalho Fernandes"***
}

\begin{abstract}
RESUMO
Em Odontopediatria deve-se atuar na promoção da saúde, prevenção de doenças e recuperação. Para isso, deve-se ter um bom planejamento e seguir etapas de um plano de tratamento. Essa sequência é passível de modificações, devendo ser um roteiro. Isso possibilita um grande sucesso terapêutico. O objetivo deste artigo é demonstrar um caso clínico desenvolvido nessa lógica, com todo o processo para chegar a um plano de tratamento, com restrições, pois o paciente apresentava diabetes tipo 1, e obter sucesso.
\end{abstract}

DESCRITORES: Planejamento de assistência ao paciente • Odontopediatria • Diabetes mellitus.

\section{ABSTRACT}

Pediatric Dentistry must act on health promotion, disease prevention and recovery. To do so, one should have good planning and follow steps of a treatment plan. This sequence is subject to change and should be a script. This provides a great therapeutic success. The purpose of this article is to demonstrate a case that worked this logic, the whole process to arrive at a treatment plan, with restrictions, because the patient had type 1 diabetes, and to get success.

DESCRIPTORS: Patient care planning • Pediatric dentistry • Diabetes mellitus.

\footnotetext{
* Especialista em Odontopediatria pela Universidade Cidade de São Paulo - UNICID.

** Coordenador do curso de especialização em Odontopediatria da Universidade Cidade de São Paulo - UNICID.

*** Professora do curso de especialização em Odontopediatria da Universidade Cidade de São Paulo - UNICID.

**** Professora do curso de especialização em Odontopediatria da Universidade Cidade de São Paulo - UNICID.
} 
NIVIA FIUZA

GERSON LOPES ANA CLAUDIA RI-

BAS CABRAL

FLÁVIA RIBEIRO de Carvalho Fer-

NANDES

PLANEJAMENTO

E PLANO DE

TRATAMENTO EM ODONTOPEDIATRIA:

RELATO DE CASO CLINICO.

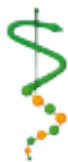

REV, ODONTOL UNIV. CID, SÃO PAULO 2016; 29(1): 6577, JAN-ABR

\section{N T RO DUÇÃO}

A abordagem odontológica no paciente infantil deve atuar em todos os níveis de prevenção, ou seja, em promoção da saúde, prevenção de doenças e na recuperação, quando as duas barreiras anteriores não obtiveram êxito. Para atuação dentro dessa proposta, é necessário o conhecimento do perfil biopsicossocial de cada paciente e também do seu núcleo familiar.

No aspecto da cárie dentária, trabalha-se com conceitos que modificam o modelo de atenção curativa para um modelo que promove saúde. Tais conceitos, segundo Bo Krasse ${ }^{1}$ (1988) e Fejerskov e $\operatorname{Kidd}^{2}$ (2005), são de: Doença Cárie (doença multifatorial, infecciosa, transmissível e dieta dependente, que produz uma desmineralização das estruturas dentárias.); Determinantes (fatores que interferem, direta ou indiretamente, no reequilíbrio do fenômeno de des-re, como: fatores salivares, imunológicos, socioeconômicos, culturais, comportamentais, microrganismo e exposição ao flúor); Lesão Cariosa (manifestação clínica da doença cárie); Risco de Cárie (probabilidade de um indivíduo desenvolver pelo menos certo número de lesões cariosas atingindo um determinado estágio de progressão durante um período específico, desde que os fatores determinantes continuem inalterados durante o período em questão) e Atividade de Cárie Dentária (Intensidade ou poder da doença - incidência de novas lesões/unidade de tempo ou progressão das lesões estabelecidas). Assim, o prontuário odontológico deve conter documentos (ficha clínica, radiografias, diário alimentar, relatórios médicos e outros) que incluam tais conceitos.

A ficha clínica deve conter identificação, antecedentes de morbidade, antecedentes familiais, exame físico geral, perfil psicológico, hábitos, métodos de utilização de flúor, histórico de traumatismo dentário, exame físico extra e intrabucal, análise das funções do sistema estomatognático, exame funcional da oclusão, avaliação dos fatores etiológicos da cárie e doença periodontal, avaliação clínica complementada com radiografias e exames laboratoriais, quando necessários.
De posse desses dados é possível identificar quais e como os determinantes estão atuando em cada paciente, assim se determinam o risco e a atividade de cárie dentária e doença periodontal, sendo possível estabelecer um plano de tratamento que aborde ações de promoção, prevenção e recuperação da saúde bucal.

Quando se avalia diferentes autores que trabalham nessa filosofia, encontramos os que dividem o plano de tratamento em diferentes fases, mas com estratégias em comum. Toledo ${ }^{3}$ (1996) e Guedes-Pinto e Issao $^{4}$ (2006), iniciam com Fase de Urgência (geralmente se referem ao controle da dor). Correa ${ }^{5}$ (2005) inicia com a Etapa Sistêmica (caso haja necessidade de algum cuidado sistêmico especial). As etapas seguintes, Adequação do Comportamento, Adequação do Meio Bucal (tem como objetivo dar condições para modificação hábitos e melhoria do meio bucal), Restauradora e Manutenção, são comuns aos autores acima citados.

No curso de Especialização em Odontopediatria da Universidade Cidade de São Paulo, UNICID, o plano de tratamento é dividido nas seguintes fases, fundamentadas em Pereira e Lopes $^{6}$ (2008): Urgência; Sistêmica; Preparatória - que se divide em Etapa Preventiva e Adequação do Meio Bucal; Adéquo-Restauradora, Restauradora e de Manutenção. (Anexo 1).

Com essa fundamentação teórica, foi realizado tratamento odontológico em paciente na clínica de especialização em Odontopediatria da UNICID, conforme descrito a seguir.

\section{CASO CLÍNICO}

Paciente GRM, 8 anos de idade, compareceu à Clínica de Especialização de Odontopediatria da UNICID, encaminhado pelo Setor de Odontologia do Hospital Municipal Menino Jesus, com a principal queixa da presença de dentes cariados e sintomatologia dolorosa, relatada pelo responsável.

$\mathrm{Na}$ anamnese, o responsável informou que o paciente é portador de Diabetes Tipo 1, diagnosticada há doze meses da data da consulta odontológica inicial e faz uso de insulina intravenosa. Em relação ao aspecto psicológico considera o 


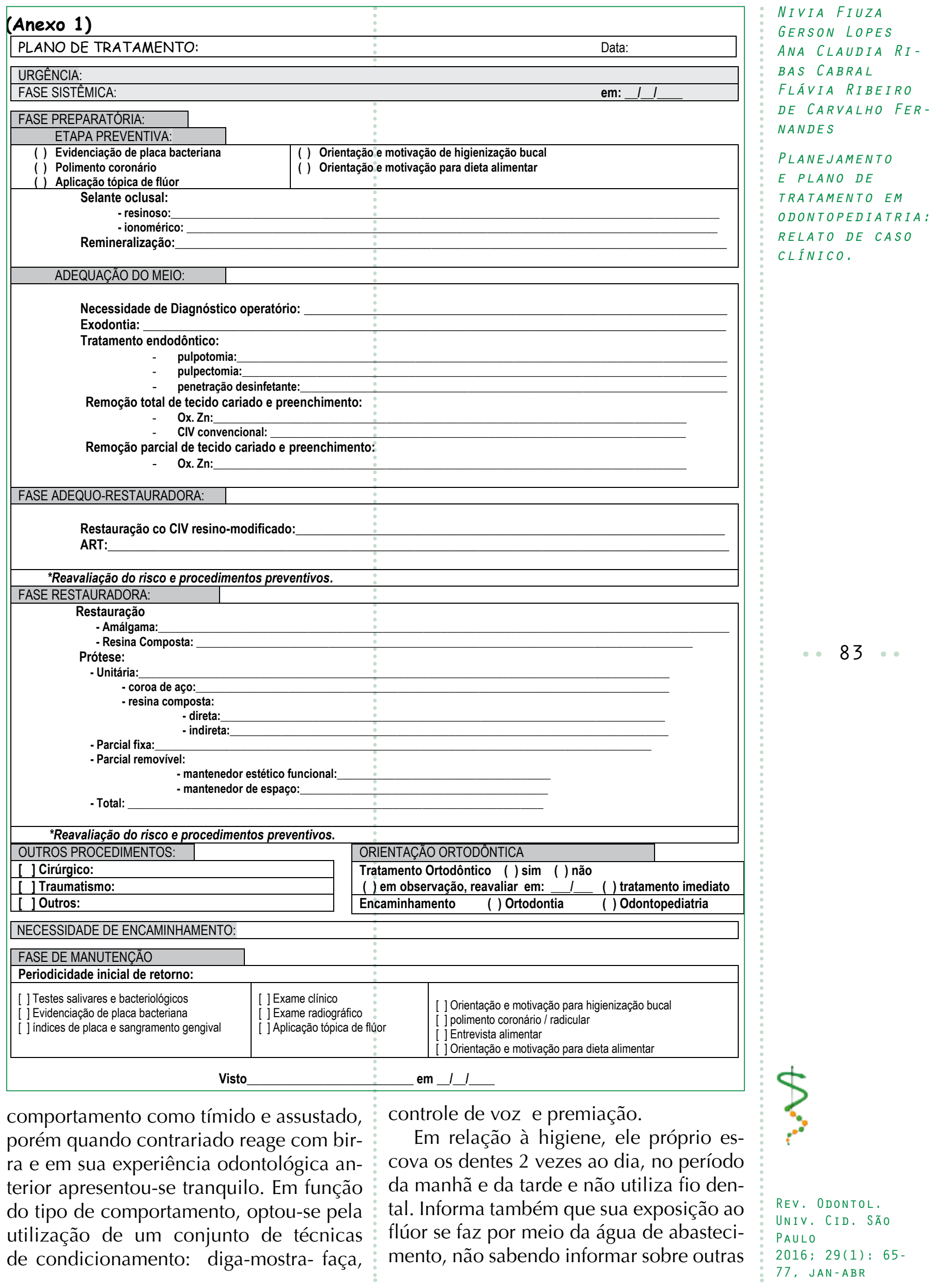



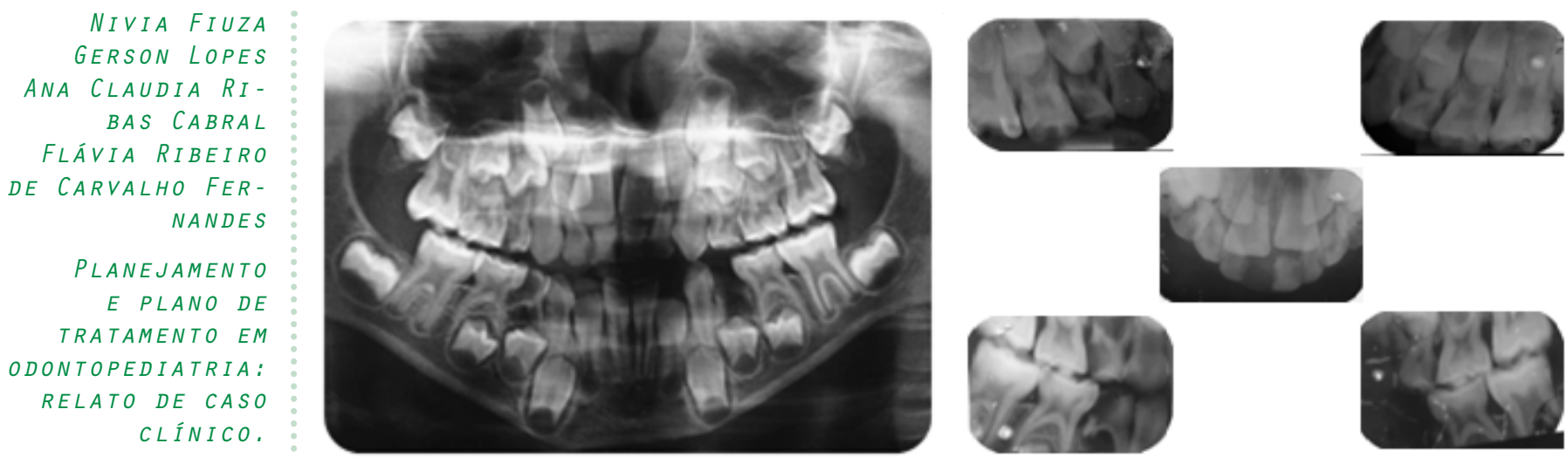

Figura 1 - Exame radiográfico.

formas de utilização.

Ao final da primeira consulta foi orientado para preencher o diário alimentar e encaminhado para realização de radiografia panorâmica. Em sua segunda consulta, avaliou-se a radiografia panorâmica, contribuindo para indicação de radiografias interproximais e periapicais de molares superiores, pois na panorâmica os molares inferiores sugeriam a indicação correta de exodontia (Fig. 1):

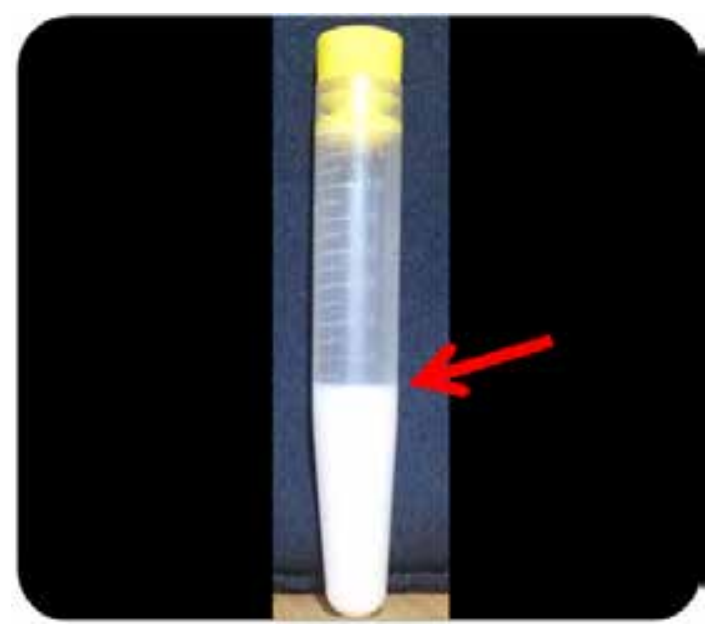

\begin{tabular}{|c|c|}
\hline \multicolumn{2}{|c|}{ Tabela de Volume de produção de Saliva } \\
\hline Classificaçăo & Faixa de Graduą̧̧o em Millitros por Minuto \\
\hline Produclo de Saliva Normal & de $1,5 \mathrm{~m} / /$ minuto ate 3,0 mil/rinuto \\
\hline Hipossalivağo Leve & de 1,05 mil/minuto ate 1,45 m/minuto \\
\hline Hipossalvasbo Moderada & de $0,55 \mathrm{~m} / \mathrm{minuto}$ ate $1,0 \mathrm{~m} / \mathrm{minu}$ (1) \\
\hline Hipossalinaçlo Severa & de 0,05 nel/minuto ate $0,50 \mathrm{~m} / \mathrm{min}$ to \\
\hline Salorrtia & acima de $3,0 \mathrm{~m} / \mathrm{min} u t \mathrm{to}$ \\
\hline
\end{tabular}
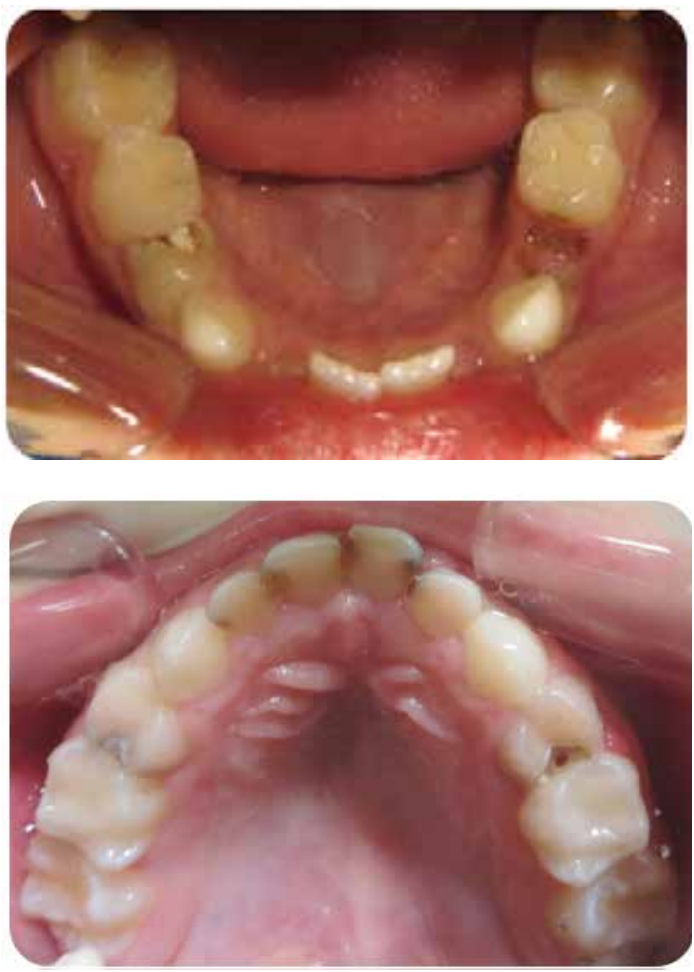

Figura 3 - Aspecto clínico inicial.

$\mathrm{Na}$ avaliação dos fatores etiológicos da cárie e doença periodontal foi utilizado o Índice de Higiene Oral Simplificado (IHO-S) de Greene e Vermillion com resultado de 1,3 considerado alto e o Índice Gengival Modificado (IGM) de Lobene et al. com resultado do índice de sangramento grau 1 com inflamação incipiente, conforme Tapia-Rivera ${ }^{7}$ (2012). Na análise do diário alimentar (Anexo 2) se observou que há ingestão racional de carboidratos, compatível com sua doença. Foi realizado o teste de fluxo salivar com estímulo, por um período de 05 minutos, alcançando $4,5 \mathrm{ml}$, dividindo o resultado por 05 para obter a quantidade em $\mathrm{ml} /$ minuto que foi 
ana Claudia Ri-

BAS CABRAL

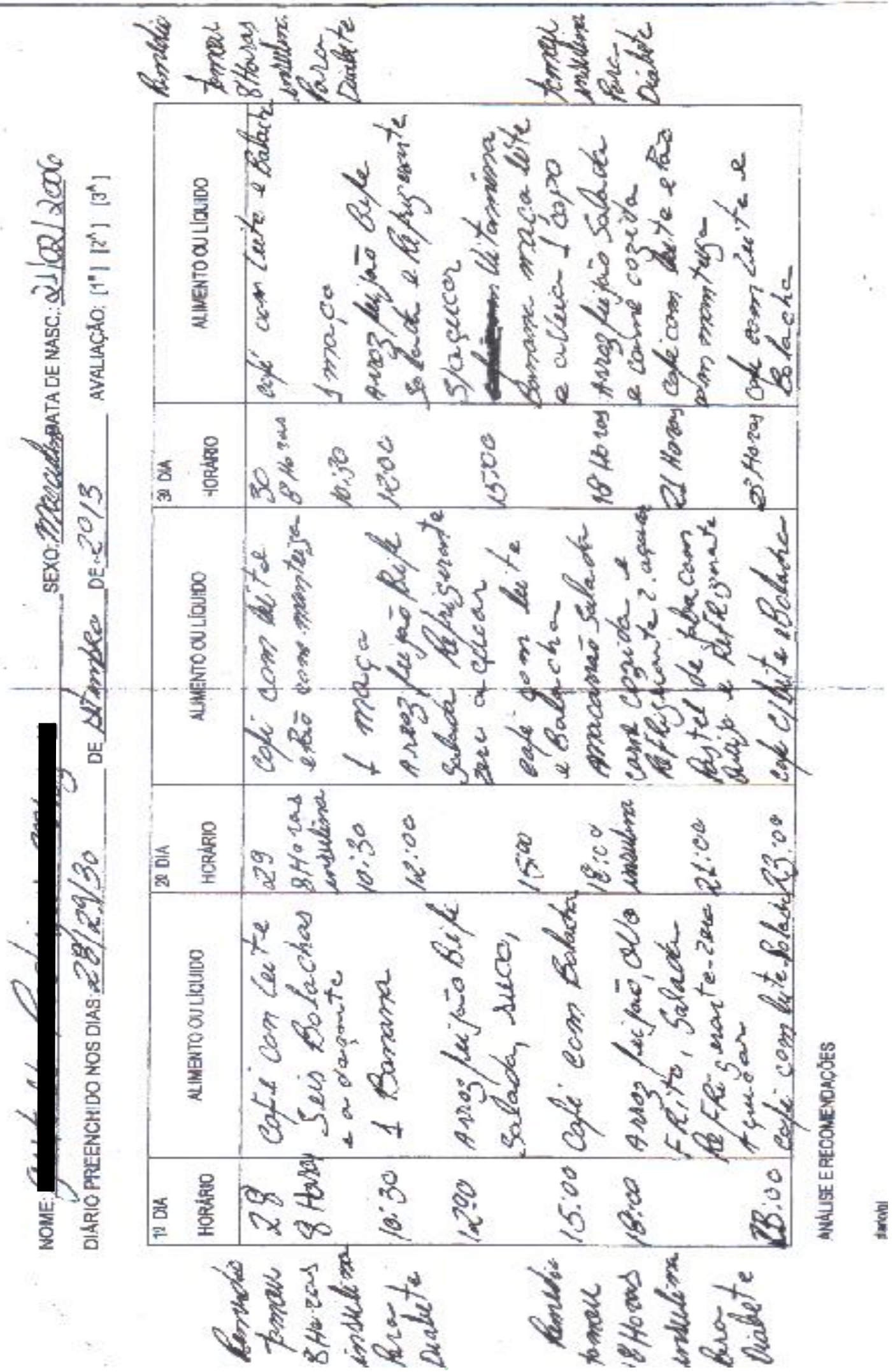

FLÁVIA RIBEIRO

de CaRvalho fER-

NANDES

Planejamento

E PLANO DE

TRATAMENTO EM

ODONTOPEDIATRIA:

RELATO DE CASO

CLINICO.

\section{5}

produzida $(0,9 \mathrm{ml} / \mathrm{m})$, conforme Conceição et al. ${ }^{8}$ (2006), observado na Figura 2.

De posse do conjunto de radiografias e após profilaxia profissional realizou-se o exame clínico, constatando-se a situação observada no (Anexo 3 e Fig. 3): 
NIVIA FIUZA

GERSON LOPES ana ClaUdia Ri-

BAS CABRAL

FLÁVIA RIBEIRO DE CARVALHO FERNANDES

PLANEJAMENTO

E PLANO DE

TRATAMENTO EM ODONTOPEDIATRIA:

RELATO DE CASO CLINICO.

REV, ODONTOL,

UNIV. CID, SÃO

PAULO:

$2016 ; 29(1): 65-$

$77, J A N-A B R$

(Anexo 3) AVALIAÇÃO CLÍNICA E RADIOGRÁFICA

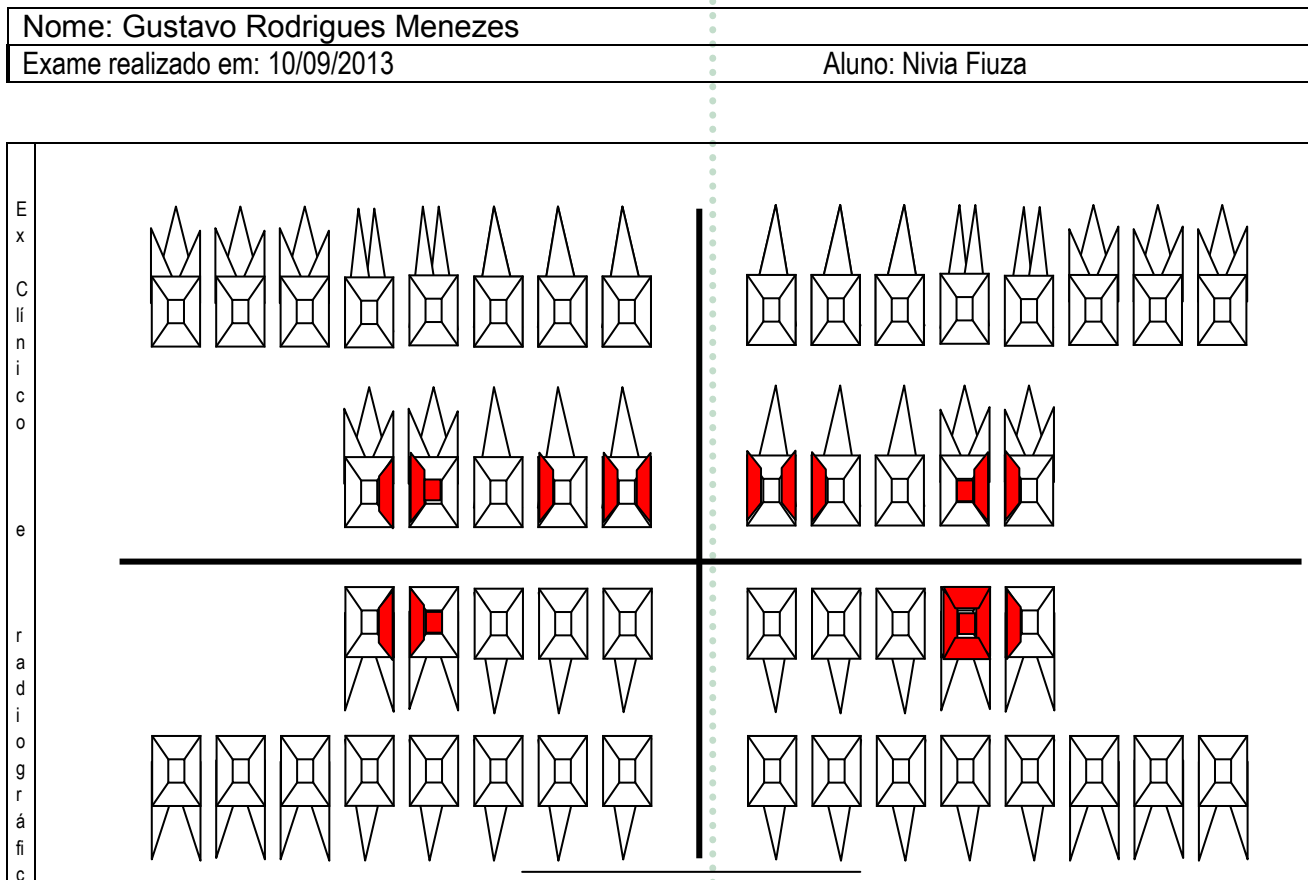

Técnicas Radiografias realizadas:

$[X]$ Periapical

$[\mathrm{X}]$ Interproximal

[ ] Oclusal

[X] Panorâmica

[ ]
1817161514131211

5554535251

8584838281

4847464544434241
2122232425262728

6162636465

7172737475

3132333435363738

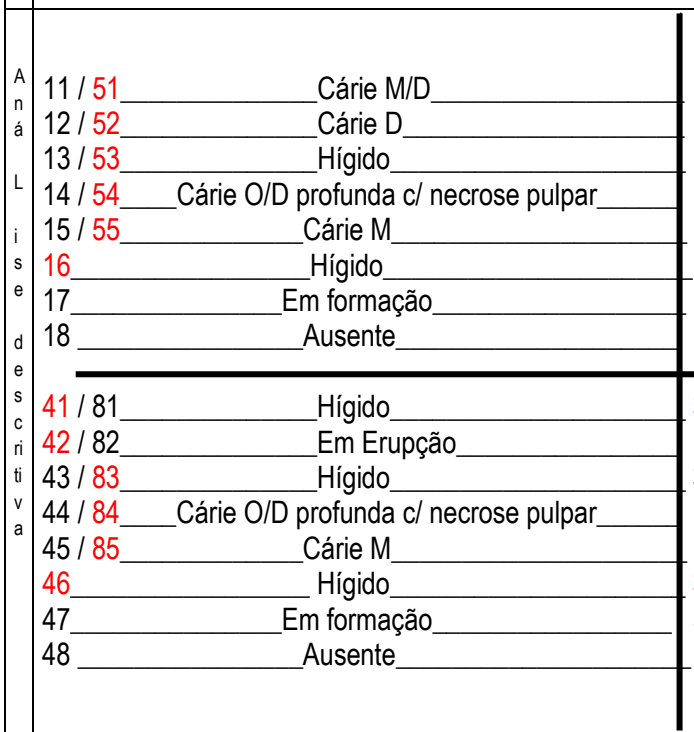

Nas avaliações complementares dos fatores de risco observou-se que apresenta idade de alto risco, apinhamento dentário, experiência anterior à cárie dentária, hipossalivação moderada em consequência da medicação para o controle da diabetes, padrão de cárie inativo, dieta de baixo ris- co e higienização inadequada com pouca exposição ao flúor, ainda considerando-se que o responsável é colaborador e a expectativa profissional seja favorável, o paciente apresenta resistência a aderir às mudanças propostas.

Assim, com esse conjunto de fatores, 


\section{(Anexo 4)}

PLANO DE TRATAMENTO: Paciente: Gustavo Rodrigues Menezes Data: $08 / 10 / 2013$

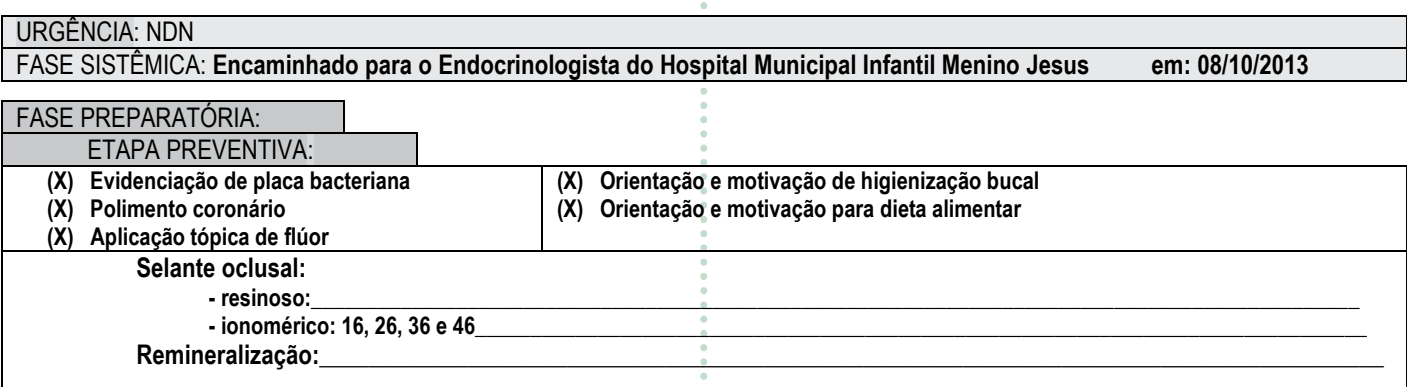

ADEQUAÇÃO DO MEIO

Necessidade de Diagnóstico operatório:

Exodontia: 54, 61, 64, 74 e 84

Tratamento endodôntico:

pulpotomia:

- pulpectomia:

penetração desinfetante:

Remoção total de tecido cariado e preenchimento:

- Ox. Zn:

CIV convencional: 52 e 62

Remoção parcial de tecido cariado e preenchimento:

- Ox. Zn:

\section{FASE ADEQUO-RESTAURADORA:}

Restauração co CIV resino-modificado: 55,65,75 e 85

ART:

${ }^{*}$ Reavaliação do risco e procedimentos preventivos.

\section{FASE RESTAURADORA}

Restauração

- Amálgama:

- Resina Composta: 52 e 62

Prótese:

- Unitária:

- coroa de aço

- resina composta:

- direta:

- Parcial fixa:

- Parcial removível:

- mantenedor estético funcional:

- Total:

- mantenedor de espaço:

${ }^{*}$ Reavaliação do risco e procedimentos preventivos. OUTROS PROCEDIMENTOS:

[ ] Cirúrgico:

[ ] Traumatismo:

[ ] Outros:

\section{NECESSIDADE DE ENCAMINHAMENTO:}

FASE DE MANUTENÇÃO

Periodicidade inicial de retorno: Mensal, por 03 meses

[ ] Testes salivares e bacteriológicos

$[X]$ Evidenciação de placa bacteriana

[X] Exame clínico

[ ] Exame radiográfico

[X] Aplicação tópica de flúor
[X] Orientação e motivação para higienização bucal

[X] polimento coronário / radicular

[X] Entrevista alimentar

[X] Orientação e motivação para dieta alimentar

Visto em $08 / 10 / 2013$

o paciente foi classificado de médio para baixo risco e baixa atividade de cárie.

Com isso, foi estabelecido o seguinte plano de tratamento (Anexo 4):

Obs.: Na fase sistêmica o paciente trouxe documento médico informando que qualquer procedimento, inclusive as exodontias, poderia ser realizado desde que sua glicemia de jejum estivesse inferior a 140mg/dl e uso de anestésicos sem adrenalina. Após conclusão, o quadro final do tratamento apresenta-se na Figura 4:
NIVIA FIUZA

GERSON LOPES

ANA ClaUdia Ri-

BAS CABRAL

FLÁVIA RIBEIRO

de CarvalHo fer-

NANDES

PLANEJAMENTO

E PLANO DE

TRATAMENTO EM

ODONTOPEDIATRIA :

RELATO DE CASO

CLINICO.
REV. ODONTOL.

UNIV, CID, SÃO

PAULO

$2016 ; 29(1): 65-$

77, JAN-ABR 


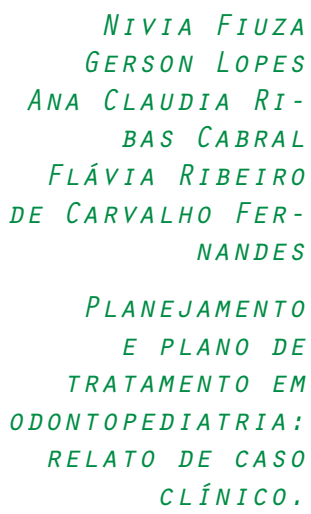

ça, lesão, determinantes, risco e atividade de cárie são ferramentas importantes para uma prática odontológica resolutiva, meIhorando a qualidade de vida dos pacientes. Mostra, ainda, que planejamento é fundamental, respeitando-se os aspectos biopsicossociais de cada criança.

No caso clínico apresentado, seguiu-se essa orientação do plano de tratamento, apenas alterado pelo índice glicêmico do paciente, conforme orientação médica, no qual devia estar até $140 \mathrm{mg} / \mathrm{dl}$.

Vale ressaltar que o paciente apresentou-se com cáries inativas decorrentes da mudança brusca de sua dieta sem sacarose, devido a sua doença sistêmica, ou seja, antes de saber que era portador de diabetes tipo 1 , possuía cáries ativas que eventualmente iriam progredir rapidamente, levando a um quadro clínico mais crítico.

O condicionamento do paciente também colaborou para o sucesso do tratamento. Após todas as consultas realizadas, com colaboração dos familiares em relação aos hábitos de higiene e com a dieta já estabilizada devido à doença sistêmica, conseguiu-se alcançar o resultado esperado e manter o baixo risco e a baixa atividade de cárie.

Atuou-se em todos os níveis de prevenção, promoção e recuperação da saúde bucal. Na UNICID foi encaminhado à Ortodontia para o tratamento corretivo, para a conclusão do plano de tratamento estabelecido, e realizadas consultas de manutenção mensal, pois a colocação do aparelho ortodôntico aumentou o risco de aparecimento de novas lesões cariosas. 
NIVIA FIUZA

GERSON LOPES

ANa Claudia RI-

BAS CABRAL

FLÁVIA RIBEIRO

DE CARVALHO FER-

NANDES

PlaneJAMENTO

E PLANO DE

TRATAMENTO EM ODONTOPEDIATRIA:

RELATO DE CASO

CLÍNICO.
São Paulo: Premier; 1996.

4. Guedes-Pinto AC, Issao M. Manual de odontopediatria. 11. ed. São Paulo: Santos; 2006.

5. Corrêa MSNP. Odontopediatria na primeira infância 2. ed. São Paulo: Santos; 2005.
6. Pereira LOA, Lopes G. Uma nova proquo-restauradora. Revista de Odontologia da Universidade Cidade de São Paulo 2008 set-dez;20(3):267-73.

7. Tapia-Rivera JG. Avaliação clínica da condições periodontais em pacientes sob tratamentos ortodôndicos convencional e lingual [Dissertação]. São Paulo: Universidade Cidade de São Paulo; 2012.

8. Conceição MD, Fagundes RL, Marocchio LS. Técnica de sialometria para uso na prática clínica diária. Rev Assoc Paul Cir Dent 2006 set.-out.;60(5):350-4.

Recebido em 21/09/2016

Aceito em 08/12/2016

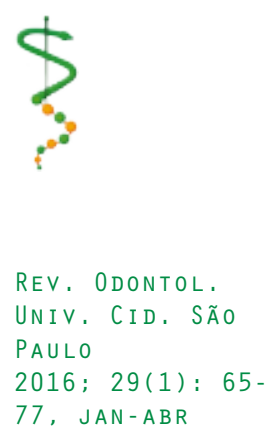

